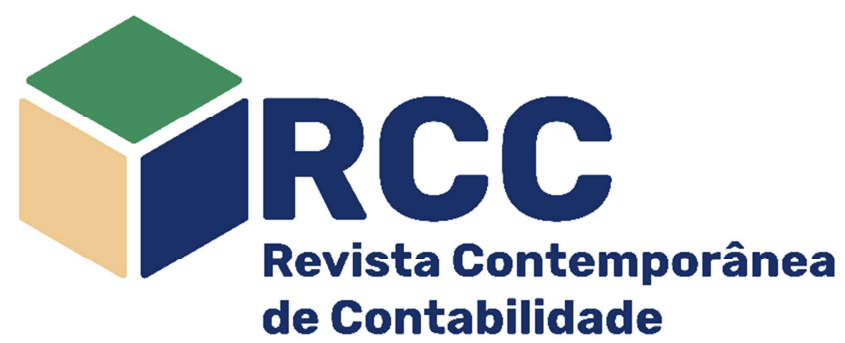

\title{
Relação entre a introdução dos principais assuntos de auditoria e o audit delay no Brasil
}

The relationship between the introduction of key audit matters and the audit delay in Brazil

\section{Relación entre la introducción de los principales asuntos de auditoría y el audit delay en Brasil}

\author{
Carlos Tadao Kawamoto* \\ Doutor em Administração (USP) \\ Servidor do Banco Central do Brasil, \\ Florianópolis/SC, Brasil \\ carlos.kawamoto@usp.br \\ https://orcid.org/0000-0002-1513-4293 (c)
}

\author{
José Alves Dantas \\ Doutor em Ciências Contábeis (UNB) \\ Professor do Programa de Pós-graduação em Ciências Contábeis \\ (UnB), Brasília/DF, Brasil \\ josealvesdantas@unb.br \\ https://orcid.org/0000-0002-0577-7340 (1)
}

Endereço do contato principal para correspondência* Av. Vereador Osni Ortiga, 2145, CEP: 88062-451 - Florianópolis/SC, Brasil

\section{Resumo}

Este estudo investigou a relação entre a introdução da seção principais assuntos de auditoria (PAA) e o audit delay dos relatórios de auditoria no Brasil. Foram analisados os dados de 122 companhias brasileiras em 2015 e 2016, primeiro ano da implementação dos PAA no país. O teste de Kolmogorov-Smirnov (KS) e o teste de sinais de Wilcoxon foram utilizados para detectar mudanças na distribuição acumulada do audit delay e em suas medianas. Também foi realizada avaliação econométrica empregando um estimador de diferença-em-diferenças (dif-in-dif). Os resultados dos testes rejeitaram a hipótese de pesquisa, sugerindo uma redução no audit delay nas empresas cujos relatórios continham seção PAA em 2016. Este trabalho preenche uma lacuna na literatura empírica nacional e documenta a relação entre o PAA e o audit delay no país, além de oferecer percepções sobre as consequências do relatório de auditoria independente sobre as demonstrações financeiras. Sob uma perspectiva teórica, o controle de insumos das firmas de auditoria se mostrou essencial para a apresentação de uma resposta definitiva sobre os impactos da introdução da seção PAA na qualidade dos serviços de auditoria, em particular, o audit delay.

Palavras-chave: Auditoria; Audit delay; Demora da Auditoria; Principais Assuntos de Auditoria

\begin{abstract}
This study investigated the relationship between the introduction of Key Audit Matters (KAM) section and the delay of audit reports in Brazil. The data from 122 Brazilian corporations in 2015, the last year without the new section, and 2016, the first year with it, were analysed. The Kolmogorov-Smirnov (KS) test and the Wilcoxon signal test were employed to detect changes in the cumulative distribution of the audit delay and its medians. The study also performed an econometric evaluation using a difference-in-difference (dif-in-dif) estimator. The results of the tests rejected the research hypothesis, suggesting a reduction in the audit delay in companies whose reports contained a KAM section in 2016. This work contributes to filling a gap in the Brazilian empirical literature by documenting the effects of KAM on the audit delay in addition to discussing the consequence of the new section on financial statements. From a theoretical perspective, the control of audit firms' inputs was revealed to be essential for the presentation of a definitive answer on the impacts of the introduction of the KAM section on the quality of audit services, particularly the audit delay.
\end{abstract}

Keywords: Audit delay; Auditing; Key audit matters; Critical audit matters

\section{Resumen}

Este estudio investigó la relación entre la introducción de los Principales Asuntos de Auditoría (PAA) y el retraso en la auditoría de los informes de auditoría en Brasil. Se analizaron datos de 122 empresas 
brasileñas en 2015 y 2016, primer año de la nueva sección. Se utilizaron el test de Kolmogorov-Smirnov (KS) y el test de señal de Wilcoxon para detectar cambios en la distribución acumulada del retardo de auditoría y sus medianas. El estudio realizó una evaluación econométrica utilizando un estimador de diferencias en diferencias. Los resultados de las pruebas rechazaron la hipótesis de investigación, sugiriendo una reducción en la demora de auditoría en empresas cuyos informes contenían una sección de PAA en 2016. Este trabajo contribuye a llenar un vacío en la literatura brasileña empírica y documentar los efectos de la PAA en la demora de auditoría y proporcionar discusiones acerca la nueva sección en los estados financieros. Desde una perspectiva teórica, el control de los insumos de las firmas de auditoría resultó fundamental para la presentación de una respuesta definitiva sobre los impactos de la introducción del apartado PAA sobre la calidad de los servicios de auditoría, en particular, el retraso en la auditoría.

Palabras clave: Auditoría; Audit delay; Retraso en la auditoría; Principales asuntos de auditoria

\section{Introdução}

A adoção de nova estrutura no relatório de auditoria independente sobre as demonstrações financeiras, a partir da publicação de um conjunto de normas profissionais - no Brasil, por meio das Normas Brasileiras de Contabilidade de Técnicas de Auditoria (NBC TA) -, foi um marco nos trabalhos de asseguração contábil, na segunda década deste milênio. 'Além do reordenamento de partes do relatório do auditor, as mudanças incluíram, em especial, a introdução da seção intitulada Principais Assuntos de Auditoria, doravante PAA.

Com o objetivo de reduzir a assimetria informacional entre os auditores e os usuários das demonstrações, a seção PAA surgiu, no Brasil, a partir da edição da NBC TA 701. Assim como a sua análoga internacional, a International Standard on Auditing (ISA) 701, a norma técnica brasileira exige dos auditores independentes a identificação dos assuntos que demandaram atenção significativa na realização da auditoria, dentre aqueles discutidos com os responsáveis pela governança da entidade auditada; e a comunicação desses assuntos em seção separada (Conselho Federal de Contabilidade [CFC], 2016).

Seções semelhantes foram adotadas nos relatórios de auditores em outros países. As chamadas Critical Audit Matters (CAM) nos Estados Unidos da América (EUA), Key Audit Matters (KAM) no Reino Unido e Irlanda e Justification des Appréciation (JDA) na França possuem estruturas e objetivos próximos daqueles descritos na NBC TA 701. Apesar de julgamentos positivos sobre os efeitos da introdução da nova seção (e.g., Cordoş \& Fülöp, 2015), alguns estudos argumentaram que ela poderia trazer impactos negativos relevantes para a qualidade do relatório do auditor ou sobre os honorários de auditoria (Sirois, Bédard, \& Bera, 2014; Bédard, Gonthier-Besacier, \& Schatt, 2019). Além desses efeitos, Sirois, Bédard e Bera (2014) exaltaram a possibilidade de a nova seção tirar a atenção do usuário sobre o restante das demonstrações financeiras; e Christensen, Glover e Wolfe (2014) alertaram que a nova seção poderia reduzir o investimento de usuários não-profissionais. Alguns autores também advogaram que a introdução da seção dos PAA elevaria o risco de responsabilização legal das firmas de auditoria, em casos de falência ou fraude em empresas auditadas (Gimbar, Hansen, \& Ozlanski, 2016; Brasel, Doxey, Grenier, \& Reffett, 2016) com os consequentes efeitos sobre os honorários de auditoria (Simunic, 1984; Dye, 1993), enquanto o Public Company Accounting Oversight Board (PCAOB, 2013) alertou para o risco de incremento no número de dias necessários para a publicação das demonstrações.

Para o Brasil, mesmo com a adoção mais recente - a partir de 2016 - já existem trabalhos sobre o assunto, com destaques para Marques e Souza (2017), que observaram maior quantidade de PAA em empresas de grande porte; Cruz, Nardi, Figueira e Silva (2019), que não identificaram padrões pré-definidos pelas firmas de auditoria nos seus relatórios; e Mello, Araújo e Luca (2021), que não encontraram variação relevante nos honorários de auditoria após a adoção dos PAA, todos alinhados com uma visão otimista que a introdução da nova seção sugeriria.

Como interesse particular, embora a obrigatoriedade dos PAA no Brasil estivesse restrita, em 2016, às companhias listadas em bolsa de valores, a partir de 2020, de acordo com a Resolução do Conselho Monetário Nacional (CMN) $n^{\circ} 4.720$, de 2019, essa seção também passou a ser obrigatória nos relatórios de auditoria das grandes instituições financeiras - enquadradas nos segmentos S1, S2 e S3, como definidos na Resolução CMN no 4.553, de 2017 - havendo o risco de ocorrer aumento no audit delay dessas entidades, e consequente ampliação no tempo de publicação ou divulgação de suas demonstrações.

Apesar de Cruz et al. (2019) não terem encontrado resultados significativos para a relação entre o audit delay e a quantidade de assuntos tratados como PAA na nova seção, uma indagação remanescente a ser verificada para o cenário brasileiro é se a mera apresentação da nova seção alterou o audit delay em 2016, primeiro ano de sua publicação. Se as introduções de seções semelhantes foram documentadas em outros países, como é o caso francês, onde se detectou uma redução do audit delay (Bédard et al., 2019), ao contrário do que se espera pela argumentação do PCAOB (2013), este trabalho procura investigar e documentar o caso brasileiro. Preenche, assim, uma lacuna da literatura sobre o tema, explorando um mercado com características particulares, i.e., o mercado brasileiro, e criando expectativas sobre o impacto 
da adoção dos PAA também para as auditorias realizadas no âmbito do sistema financeiro a partir das demonstrações relativas ao exercício de 2020.

Neste contexto, o presente estudo tem como objetivo verificar a relação entre a introdução da seção com os PAA e o audit delay dos relatórios de auditoria das empresas de capital aberto brasileiras. Para esse fim, foram promovidas análises estatísticas sobre a variável audit delay em dados de uma amostra de 122 companhias brasileiras de diferentes setores, sendo definida como o tempo, medido em dias, entre o fim do período fiscal e o dia da assinatura do relatório dos auditores, como em Ashton, Willingham e Elliot (1987) e Ng e Tai (1994).

A primeira bateria de exames contemplou testes não-paramétricos, dentre eles uma comparação da distribuição acumulada das estatísticas de audit delay das companhias da amostra através do teste de Kolmogorov-Smirnov (KS), usualmente adotado para se avaliar a normalidade de uma distribuição. Adicionalmente, foi realizado o teste de sinais de Wilcoxon, aferindo as medianas dos audit delay. Em ambos os testes, comparou-se o primeiro ano de exigência de publicação da seção PAA, i.e., 2016, com o período imediatamente antecedente, i.e., 2015. Em complemento aos testes não-paramétricos, realizou-se uma avaliação econométrica, que permite o controle de algumas variáveis que potencialmente impactam sobre o audit delay, medindo o efeito da introdução da nova seção com um estimador de diferenças-emdiferenças (dif-in-dif) aplicado ao painel construído.

Os resultados refutaram a hipótese de que a introdução da seção PAA gerou impacto negativo sobre o audit delay, i.e., aumento no número de dias para a assinatura do relatório dos auditores das empresas analisadas. Em linha com o resultado do caso francês (Bédard et al., 2019), as análises sugeriram que os auditores, ao elaborarem seus relatórios de asseguração das demonstrações financeiras, finalizaram seus processos tempestivamente mesmo após a implementação da nova seção.

O estudo é essencialmente empírico e contribui ao documentar os efeitos da nova seção sobre o audit delay no Brasil, possibilitando aos reguladores de mercado e da profissão o conforto de que o aprimoramento do produto final do trabalho dos auditores não resultou em consequência negativa relacionada ao tempo para emissão do relatório de auditora. Embora sejam identificadas pesquisas que examinaram a relação entre audit delay e a adoção de seções semelhantes às do PAA em outros países, não há evidências de trabalhos a respeito no mercado brasileiro. Em adição, o estudo oferece uma base de avaliação da introdução da seção PAA em entidades ainda não alcançadas pela nova exigência. Por fim, a aplicação atípica do teste KS no contexto dos PAA pode servir como uma contribuição metodológica para outros trabalhos do gênero.

Sob o ponto de vista teórico, seguindo Copley, Gaver e Gaver (1995), entende-se que a avaliação dos determinantes dos resultados de uma auditoria, quer seja em termos de entrega tempestiva, como é o caso deste estudo, ou dos honorários resultantes, deve contemplar tanto o lado da oferta quanto o da demanda. Nesse sentido, na medida em que a introdução da nova seção, imposta pelo regulador, representa um aumento nos serviços de auditoria, uma avaliação do novo equilíbrio resultante necessitaria, necessariamente, da consideração simultânea de elementos da oferta. Por isso, não foi possível inferir, de maneira conclusiva, sobre a ocorrência de deslocamento da força de trabalho dentro das firmas de auditoria em direção aos trabalhos em que a nova seção era requerida, deixada como conjectura para avaliações posteriores em direção a uma explicação para a redução no audit delay observado.

O texto foi estruturado em cinco seções, incluindo esta introdução, com a contextualização do tema, a identificação do objetivo e a discussão sobre a relevância e contribuições do estudo. A segunda seção se dedica à revisão da literatura sobre o atributo tempestividade e o audit delay, além de discutir a introdução dos PAA no Brasil e em outros países. A terceira seção apresenta os procedimentos metodológicos desenvolvidos para a realização dos testes empíricos, enquanto a quarta descreve e analisa os principais resultados obtidos. $O$ artigo é finalizado com a exposição das conclusões e sugestões para estudos futuros.

\section{Referencial Teórico}

Esta seção apresenta uma breve revisão do referencial teórico e dos conceitos fundamentais aplicados ao trabalho, contemplando o audit delay e sua relação com os principais assuntos de auditoria.

\subsection{Audit Delay}

Considerada por Abbott, Parker e Peters (2012) como o principal determinante do critério tempestividade de uma demonstração financeira, o audit delay já foi associado a indícios de riscos de falhas de controle interno, adoção de políticas contábeis equivocadas ou erros nas demonstrações financeiras (Kinney Jr \& McDaniel, 1993). Apesar dos determinantes do audit delay ainda serem discutidos, parece consensual a ideia de que a publicação além do prazo legal fornece sinalização negativa ao mercado, possivelmente de forma similar à qualificação de opinião (Blankley, Hurtt, \& MacGregor, 2015).

Dyer IV e McHugh (1975) estão entre os primeiros a estruturarem o processo de asseguração desde o fim do período fiscal até a publicação de demonstrações financeiras auditadas. Com base no prazo de entrega das declarações financeiras e nas respostas de questionários enviados para empresas 
auditadas e firmas de auditoria, os autores construíram a estrutura temporal do audit delay replicada na Figura 1, que subdivide a defasagem total em quatro componentes, A, B, C e D, mais o período de envio do relatório pelo correio (sem letra atribuída), que era prática comum à época do trabalho. $O$ componente $A$ representa o número de dias até o auditor poder auditar ao menos $90 \%$ das contas do balanço; $\mathrm{B}$, o número de dias entre o fim do período $\mathrm{A}$ e o envio do relatório para o comitê de auditoria; $\mathrm{C}$, o número de dias entre o envio do relatório para o comitê e o recebimento de devolutiva para ajustes, incluindo o tempo para as negociações com o cliente; e $\mathrm{D}$, o número de dias para a emissão do relatório final.

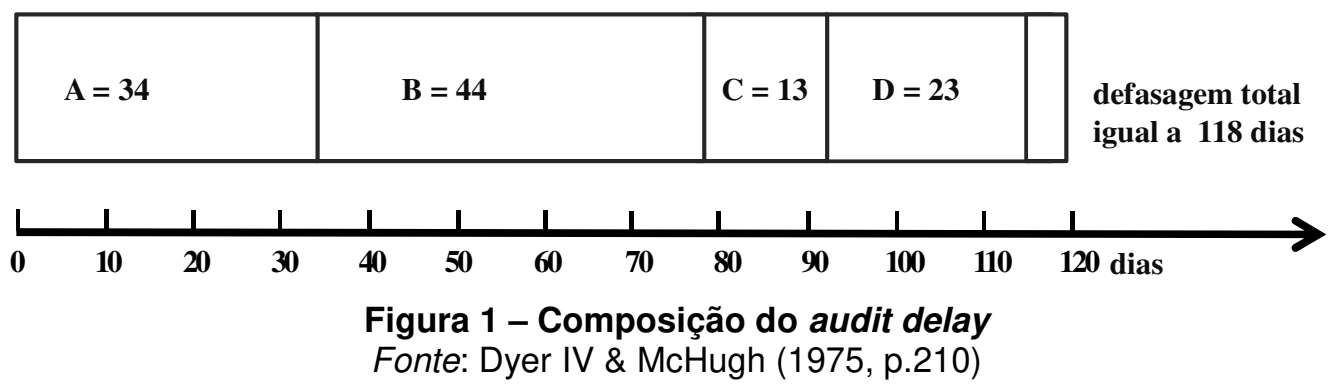

Em tempos mais contemporâneos, os componentes do audit delay podem ser estruturados diferentemente ou possuir outros valores. No início de 2021, momento em que este artigo estava sendo escrito, os autores não conheciam um único país que exigia o envio de demonstrações financeiras por correio. Associado aos avanços tecnológicos observados desde a elaboração do estudo de Dyer IV e McHugh (1975), a realização de testes de controle durante o ano fiscal e o encurtamento do tempo exigido para a entrega de relatórios financeiros imposto por alguns reguladores implicaram diminuição significativa da defasagem total (Bryant-Kutcher, Peng, \& Weber, 2013). Em 2003, por exemplo, a SEC reduziu o prazo de submissão de relatórios financeiros para firmas qualificadas, usualmente de grande porte, chamadas large accelerated fillers. Desde 2006, o prazo máximo para o envio das demonstrações de empresas dessa categoria nos EUA passou a ser 60 dias.

A literatura empírica é profícua em discriminar determinantes do audit delay e revelar a significância de algumas variáveis observáveis. Abernathy, Barnes, Stefaniak e Weisbarth (2017) realizaram revisão extensa da literatura e exaltaram o fato de que tanto as especificidades da firma de auditoria como as da corporação auditada são fatores importantes que devem ser incluídos em avaliações empíricas. Ademais, parece evidente que não apenas as entidades individualmente são relevantes, mas também a relação entre a firma de auditoria e a corporação auditada no processo de asseguração. Braunbeck (2010), por exemplo, associou o audit delay à independência da firma do auditor, uma vez que a demora estaria relacionada à negociação entre o auditor e seu cliente acerca de ajustes nas demonstrações contábeis, sobre as quais emitiu sua opinião.

Como variável característica das empresas auditadas, uma medida amplamente aplicada na literatura empírica é o tamanho da corporação, usualmente representada pelos ativos totais. Estudos sobre os mercados da Austrália (Dyer IV \& McHugh, 1975), EUA (Givoly \& Palmon, 1982), Canadá (Ashton, Willingtam, \& Elliott, 1987), Hong Kong (Ng \& Tai, 1994), França (Khoufi \& Khoufi, 2018) e Espanha (Bonsón-Ponte, Escobar-Rodríguez, \& Borrero-Dominguez, 2008) revelaram resultados quase unânimes de que empresas maiores possuem menor audit delay. Na medida em que grandes corporações têm acesso a maior quantidade de recursos e melhores sistemas de controle, conseguem produzir relatórios contábeis mais confiáveis e tempestivos. Os resultados de estudos que investigam variáveis associadas às estruturas de controle interno ou de comitês de auditoria tendem a corroborar a argumentação sobre o tamanho da corporação (Ashton et al., 1987; Abbott, Parker, \& Peters, 2012; Pizzini, Lin, \& Ziegenfuss, 2015).

Outra característica relevante do audit delay é a especificidade do setor em que atua a empresa auditada. Ashton et al. (1987) apontaram para a existência de controles mais rigorosos em instituições financeiras, sujeitas a normatizações específicas em diferentes jurisdições, sendo usual encontrar bancos entre os primeiros em cronogramas de divulgação das demonstrações financeiras.

Em relação às características associadas às firmas de auditoria ou ao próprio relatório do auditor, a literatura sinaliza para a importância da qualificação das opiniões, com relatórios sem opinião qualificada ou "limpos" apresentando menores audit delay do que os demais (Whittred, 1980; Ashton et al., 1987; Begley \& Fischer, 1998; Haw, Qi, \& Wu, 2000).

Para empresas listadas do Brasil, Pereira e Costa (2012) encontraram associações entre opiniões qualificadas e maior audit delay. Na mesma direção, Ramos e Cunha (2015) concluíram que firmas com comitês de auditoria estruturados e com nível de governança mais sofisticado, i.e., integrantes do denominado Novo Mercado, exibiram menor atraso da auditoria, mas não corroboraram a hipótese proposta de que o rodízio de firmas de auditoria tenha efeito significativo sobre o audit delay.

O texto prossegue explorando as características da nova seção exigida no relatório dos auditores, e apresenta os resultados dos principais trabalhos empíricos que avaliaram o impacto da introdução da seção PAA, com foco sobre o audit delay, lançando base para a formulação da hipótese de pesquisa. 


\subsection{Principais Assuntos de Auditoria e sua Relação com o Audit Delay}

Dentre as recentes alterações promovidas pelo International Auditing and Assurance Standards Board (IAASB) nos relatórios de auditoria se destaca a emissão do padrão ISA 701, com mudanças no formato e no conteúdo do relatório dos auditores de maneira a produzir um documento mais informativo. Diversos países realizaram modificações em seus relatórios de auditoria com adoção de seção análoga à dos PAA antes mesmo da publicação do ISA 701. Apesar de haver pequenas variantes entre as seções adotadas nos diferentes países, todas foram consideradas alterações relevantes nos relatórios de auditoria (Kiss, Fülöp, \& Cordoş, 2015; PCAOB, 2017).

$\mathrm{Na}$ França, a seção análoga à dos PAA, a JDA, foi adotada nos relatórios de auditoria de empresas francesas de grande porte em 2006 (Haut Conseil du Commissariat aux Comptes [H3C], 2006). Bédard, Gonthier-Besacier e Schatt (2019) avaliaram custos e benefícios da JDA e seus resultados sugeriram que a introdução da seção não mostrou impacto significativo sobre o número de dias necessários à publicação, sobre os honorários dos auditores e sobre a qualidade da auditoria medida pelas acumulações (accruals) em um modelo de gerenciamento dos resultados. Visto em termos nominais, o número de dias para a publicação dos relatórios dos auditores com a introdução da seção JDA chegou a ser reduzido.

Nos EUA, a seção CAM foi inicialmente proposta pelo PCAOB em 2013, sendo considerada o elemento mais significativo do novo padrão recomendado para o relatório de auditoria com opinião nãoqualificada (PCAOB, 2013, p.A7-1). De maneira sucinta, os CAM são os assuntos que requereram julgamento significativo do auditor para ser avaliado ou as áreas que mostraram maior dificuldade na avaliação ou obtenção de evidência durante o processo de auditoria. Apesar do objetivo explícito de melhoria na informação provida pelos auditores, o PCAOB não deixou de ponderar aspectos negativos relativos aos CAM, que exigiriam esforços adicionais sobre o processo de auditoria. Com isso, havia 0 receio de a introdução da seção CAM gerar necessidade de tempo adicional para a revisão final das comunicações, implicando em redução no período disponível para o auditor concluir seu relatório (PCAOB, 2013). Dentre as avaliações empíricas conhecidas, Gimbar, Hansen e Ozlanski (2016) estudaram os efeitos da adoção de CAM nos EUA e suas conclusões sugeriram baixa possibilidade de contingência passiva sobre os auditores com a introdução da nova seção.

No Brasil, a aprovação da NBC TA 701 ocorreu em junho de 2016, produzindo efeito a partir do exercício de 2016, apenas para as empresas listadas. Alguns reguladores, como a Comissão de Valores Mobiliários (CVM) e o CMN, só se pronunciaram sobre o assunto após aquele ano. A Instrução CVM no 591 , que impõe a comunicação da nova seção nos relatórios de auditoria de demonstrações financeiras de todas as entidades reguladas ou supervisionadas pela CVM, foi publicada em outubro de 2017 (CVM, 2017). A obrigatoriedade de apresentação da seção PAA para fundos de investimento só ocorreu em 2019 (CVM, 2019), mesmo ano em que o CMN introduziu a exigência de publicação da nova seção, com vigência a partir de 2020, nos relatórios de auditoria de instituições financeiras dos segmentos S1, S2 e S3, além daquelas instituições que, mesmo fora desses três segmentos, sejam constituídas sob a forma de companhia aberta.i

Apesar de essas mudanças serem recentes, algumas avaliações empíricas do caso brasileiro já foram publicadas. Silva, Bianchi e Venturini (2018), por exemplo, examinaram as demonstrações de firmas do setor de energia elétrica e encontraram ao menos um PAA em todas as empresas auditadas. Ao analisarem amostra de 49 empresas listadas na B3, Marques e Souza (2017) sintetizaram os principais assuntos selecionados como PAA, constatando, dentre outros resultados, que a maioria dos relatórios continha de dois a quatro PAA, sendo a recuperabilidade de ativos, contingências e reconhecimento de receitas os temas mais abordados. Os autores observaram especificidades para entidades do segmento financeiro, resultado endossado por Santana, Silva, Dantas e Botelho (2019).

Cruz et al. (2019) examinaram a relação entre o conteúdo do novo relatório de auditoria e o perfil das empresas auditadas e das firmas de auditoria. Após exame do relatório auditoria de 346 empresas listas na bolsa brasileira para o exercício de 2016, primeiro ano de aplicação do novo relatório de auditoria, que inclui a seção PAA, os autores não observaram padrões pré-definidos pelas firmas de auditoria em seus relatórios, em visão otimista sobre os resultados da adoção da nova seção. De interesse particular para este trabalho, não encontraram resultados significativos para a relação entre o audit delay e a quantidade de PAA.

Além deles, destacam-se: o trabalho de Camargo, Rodrigues, Machado e Guerra (2019), que encontrou seções de PAA com mais palavras em empresas que apresentaram prejuízo em comparação com aquelas que mostraram lucros, sugerindo que há valor informativo com a nova seção; o estudo de evento de Alves e Galdi (2020), que considerou uma janela de evento de três dias, incluindo a data da divulgação, e encontrou retornos extraordinários para a publicação de demonstrações no primeiro ano da adoção da nova seção; e o paper de Mello et al.(2021), que não detectou impacto sobre os honorários dos auditores após a introdução da seção PAA. No entanto, nenhum deles avaliou os efeitos da nova seção sobre o audit delay.

Sendo o audit delay o tempo de entrega do serviço de auditoria, a introdução de nova seção no relatório de auditoria pode ser entendida como demanda adicional no serviço de auditoria. Como 
consequência da imposição de condição ceteris paribus, algum efeito incremental sobre o audit delay poderia ser esperado. Com o mesmo esforço, a introdução de tarefa adicional no serviço implicaria em aumento no tempo necessário para a sua execução. Obviamente, esse resultado confronta-se à ideia de que o novo serviço requerido com a introdução da seção PAA seria apenas um pequeno esforço adicional para divulgação de novo item no relatório do auditor, não impactando na quantidade de horas consumidas na auditoria (Reid, Carcello, Li \& Neal, 2019; Mello, Araújo \& Luca, 2021).

De qualquer modo, reforça-se aqui o aspecto da condição ceteris paribus pois, sem ela, um resultado líquido nulo sobre o audit delay poderia acontecer mesmo se a nova seção não gerasse apenas um pequeno esforço adicional, mas onerasse os custos dos auditores de maneira material. Por exemplo, caso a produção da nova seção ampliasse o número de horas trabalhadas pelos auditores, incluísse maior proporção de auditores sêniores (i.e, partners ou gerentes) no engagement, ou gerasse maior provisão de serviços auxiliares (Knechel \& Payne, 2001), os relatórios com a seção PAA poderiam ser produzidos com manutenção ou até redução no audit delay. Alternativamente, o aumento do risco do cliente, caso assim fosse percebida a introdução da seção PAA, poderia ser internalizado com menores margens de lucro para os auditores. Nessa linha, o resultado sobre os preços praticados ou a qualidade do serviço oferecido dependeria de uma avaliação simultânea de fatores da demanda e da oferta, como reforçado por Copley et al. (1995). Ao se analisar somente uma das curvas que formam o mercado de auditoria, deixamos de oferecer medidas corretas sobre os deslocamentos entre equilíbrios. Nesse sentido, alguns dos estudos avaliados que exploram o audit delay, incluindo este próprio, que não controlam elementos dos dois agentes que formam o mercado de auditoria, devem ser vistos com ressalva.

Em resumo, as evidências da literatura empírica brasileira parecem caminhar alinhadas às internacionais, que sugerem efeito positivo com a introdução dos PAA, ainda que haja dúvidas da sua relevância sobre a qualidade percebida dos relatórios dos auditores. Apesar disso, a importância da tempestividade das demonstrações financeiras instiga uma avaliação formal da introdução da nova seção sobre o audit delay para o caso brasileiro, a despeito das dificuldades de avaliação mencionadas acima. Cruz et al. (2019) avaliaram o número de assuntos e sua relação com o audit delay, mas não observaram eventuais incrementos antes e depois da introdução da nova seção. Nessa direção e em complemento ao trabalho citado, é formulada a seguinte hipótese de pesquisa, a ser testada empiricamente:

Hipótese de pesquisa: A introdução da seção PAA está associada a um aumento no audit delay dos relatórios de auditoria das companhias abertas brasileiras.

Sob o ponto de vista das firmas de auditoria, além do prazo necessário à identificação e descrição dos PAA, parece ser necessário maior tempo de discussões com a corporação auditada, especialmente levando-se em conta eventual apreensão por parte dessa no que se refere a possíveis repercussões associadas à divulgação dos PAA. Sob a perspectiva microeconômica comentada anteriormente, a introdução da seção PAA em 2016 implicaria, mantidas constantes as condições de equilíbrio de 2015, em um aumento nos honorários de auditoria ou redução na qualidade final do serviço, aqui percebida como o audit delay. Assim, torna-se razoável supor que a introdução da nova seção adiciona uma tarefa ao processo de auditoria e, por isso, gera aumento no tempo requerido para a finalização do processo de toda a auditoria.

\section{Procedimentos Metodológicos}

A análise da hipótese formulada é baseada em ferramental estatístico e econométrico, selecionado a partir da disponibilidade de informações coletadas. Tais procedimentos são expostos nesta seção, juntamente com uma descrição dos dados empregados.

\subsection{Fonte de Dados e Variáveis}

Para a realização dos testes empíricos foram coletadas informações de 122 entidades e de suas demonstrações financeiras para os anos fiscais de 2015 e 2016. Todos os documentos foram extraídos diretamente do sítio eletrônico de cada corporação, ou da B3. Na ausência de informação na demonstração financeira de uma corporação, recorreu-se à Demonstração Financeira Padronizada (DFP) exigida pela CVM. Além da data de assinatura do relatório do auditor independente em cada documento, foram capturados os dados apresentados na Tabela 1.

A amostra contempla tanto empresas listadas na B3 e pertencentes ao Índice Bovespa, como empresas de capital fechado, sendo construída sem um processo formal de amostragem, formando uma amostra por conveniência, contemplando empresas que publicaram e não publicaram seção de PAA em seus relatórios de auditoria nas demonstrações financeiras de 2016. Após o processo de coleta da amostra iniciar com os dados de empresas do índice Bovespa em julho de 2019, com cotações públicas em 2015, ampliou-se a amostra com dados de instituições bancárias do país, capturados por ordem decrescente de ativo total. 
Tabela 1

Descrição das variáveis consideradas no estudo

\begin{tabular}{|c|c|c|}
\hline Código & Descrição & Fonte \\
\hline$A D L$ & $\begin{array}{l}\text { Número de dias entre o fim do período fiscal e o dia da assinatura do relatório dos } \\
\text { auditores. }\end{array}$ & $\begin{array}{l}\text { Relatório dos } \\
\text { auditores } \\
\text { independentes }\end{array}$ \\
\hline$P A A$ & $\begin{array}{l}\text { Dummy para identificar as entidades que apresentaram a seção PAA nos relatórios } \\
\text { de auditores independentes no ano fiscal de } 2016 . P A A=1 \text { se o relatório da empresa } \\
\text { continha PAA em } 2016 \text {, e } 0 \text { caso contrário. }\end{array}$ & $\begin{array}{l}\text { Relatório dos } \\
\text { auditores } \\
\text { independentes }\end{array}$ \\
\hline ANO & $\begin{array}{l}\text { Dummy para o primeiro ano em que empresas listadas se tornaram obrigadas a } \\
\text { publicar relatórios de auditoria com a seção PAA. ANO =0 para ano fiscal de } 2015 \text {, e } \\
1 \text { para } 2016 \text {. }\end{array}$ & $\begin{array}{l}\text { Relatório dos } \\
\text { auditores } \\
\text { independentes }\end{array}$ \\
\hline LNAT & Logaritmo natural do valor total dos ativos, em $\mathrm{R} \$$ bilhão, da corporação auditada. & $\begin{array}{l}\text { Demonstrações } \\
\text { Financeiras }\end{array}$ \\
\hline GC & $\begin{array}{l}\text { Dummy para empresa pertencente a grupo de governança corporativa da } B 3 . G C=1 \\
\text { se corporação auditada pertencer ao nível } 1 \text {, nível } 2 \text { ou novo mercado de } \\
\text { classificação da } \mathrm{B} 3, \text { e } 0 \text { caso contrário. }\end{array}$ & B3 -1 \\
\hline IBOV & $\begin{array}{l}\text { Dummy para empresa pertencente ao índice Bovespa. IBOV }=1 \text { se as ações da } \\
\text { corporação auditada pertencerem ao índice Bovespa, e } 0 \text { caso contrário. }\end{array}$ & "B3 \\
\hline FIN & $\begin{array}{l}\text { Dummy para empresa pertencente ao setor financeiro. FIN = } 1 \text { se corporação } \\
\text { auditada for do setor financeiro, e } 0 \text { caso contrário. }\end{array}$ & B3 \\
\hline$O Q$ & $\begin{array}{l}\text { Dummy para a presença de opinião qualificada ou abstenção de opinião. } O Q=1 \text { se } \\
\text { a opinião do relatório do auditor for qualificada (i.e., com ressalva ou adversa) ou } \\
\text { com abstenção de opinião, e } 0 \text { caso contrário (i.e., a opinão for não qualificada ou } \\
\text { "limpa"). }\end{array}$ & $\begin{array}{l}\text { Relatório dos } \\
\text { auditores } \\
\text { independentes }\end{array}$ \\
\hline BIG4 & $\begin{array}{l}\text { Dummy para as firmas de auditoria pertencentes ao grupo denominado Big } 4 \text {, } \\
\text { composto por Deloitte, EY, KPMG e PwC, e } 0 \text { caso contrário. }\end{array}$ & $\begin{array}{l}\text { Relatório dos } \\
\text { auditores } \\
\text { independentes }\end{array}$ \\
\hline
\end{tabular}

Apesar de a amostra ser não-aleatória e, por isso, não permitir inferências dos resultados sobre a população das empresas brasileiras, ela é satisfatória para a avaliação dos impactos da seção do PAA sobre o audit delay. Um breve resumo estatístico dos dados coletados é apresentado na Tabela 2.

Tabela 2

Estatísticas descritivas das variáveis

\begin{tabular}{|c|c|c|c|c|c|c|}
\hline Variável & Medida & Obs. & Média & $\begin{array}{l}\text { Desvio } \\
\text { padrão }\end{array}$ & Mínimo & Máximo \\
\hline$\overline{A D L}$ & Número de dias & 244 & 82,080 & 95,020 & 21,00 & 814,00 \\
\hline$P A A$ & binária - dummy & 244 & 0,664 & 0,473 & 0,00 & 1,00 \\
\hline ANO & binária - dummy & 244 & $0,500^{*}$ & 0,501 & 0,00 & 1,00 \\
\hline LNAT & log. natural de $R \$$ (milhão) & 244 & 16,730 & 1,460 & 14,33 & 21,06 \\
\hline GC & binária - dummy & 244 & $0,541^{*}$ & 0,499 & 0,00 & 1,00 \\
\hline FIN & binária - dummy & 244 & $0,516^{*}$ & 0,501 & 0,00 & 1,00 \\
\hline IBOV & binária - dummy & 244 & $0,361^{*}$ & 0,481 & 0,00 & 1,00 \\
\hline$O Q$ & binária - dummy & 244 & $0,098^{*}$ & 0,298 & 0,00 & 1,00 \\
\hline BIG4 & binária - dummy & 244 & $0,967^{*}$ & 0,178 & 0,00 & 1,00 \\
\hline
\end{tabular}

Legenda: representa o percentual de respostas igual a 1.

No total, foram consideradas informações de 122 companhias, sendo que 81 delas apresentaram a nova seção nos relatórios de suas auditorias independentes nas demonstrações de 2016. Algumas distribuições por subgrupos amostrais são exibidas na Tabela 3.

Tabela 3

Frequência na amostra por subgrupos

\begin{tabular}{|c|c|c|c|c|}
\hline & & Bancos & Outros segmentos & Total da amostra \\
\hline & Listadas & 4 & 2 & 6 \\
\hline \multirow[t]{2}{*}{ Sem PAA em 2016} & Não listadas & 33 & 2 & 35 \\
\hline & Total subgrupo & 37 & 4 & 41 \\
\hline \multirow{3}{*}{ Com PAA em 2016} & Listadas & 17 & 55 & 72 \\
\hline & Não listadas & 9 & 0 & 9 \\
\hline & Total subgrupo & 26 & 55 & 81 \\
\hline Total da amostra & & 63 & 59 & 122 \\
\hline
\end{tabular}

Do total, 78 empresas eram listadas e 44 fechadas; e, 63 eram bancos e 59 empresas de outros setores. Das 81 empresas que apresentaram a seção PAA em seus relatórios de auditoria independente do ano fiscal 2016, 72 eram listadas, sendo 17 dessas do setor financeiro e 55 de outros setores. Dos 63 
bancos presentes na amostra, 37 deles não apresentaram a nova seção em seus relatórios de auditoria independente. A lista completa das companhias contempladas na amostra é apresentada no Apêndice.

\subsection{Métodos Empregados}

A principal estatística da pesquisa é o $A D L$, que expressa o audit delay e é o foco principal deste estudo. Ela será empregada como variável dependente nas estimações econométricas. Conforme destacado na Tabela 1, o audit delay é definido como o número de dias entre o fim do período fiscal e o dia da assinatura do relatório dos auditores, como em Ashton et al. (1987) e $\mathrm{Ng}$ e Tai (1994).

Apesar de haver críticas pertinentes sobre o uso do número de dias como proxy para se avaliar os determinantes do audit delay, a métrica ainda é a mais utilizada nesta tarefa (e.g., Davies \& Whittred, 1980; Ashton et al., 1987; $\mathrm{Ng} \&$ Tai, 1994; Abbott et al., 2012). Sua disponibilidade, em contrapartida a métricas alternativas como o tempo despendido exclusivamente na execução da auditoria (i.e., excluindo o tempo de negociação do processo de auditoria), tornou seu uso popular. Ademais, há razoáveis evidências de que grande parte do tempo total de publicação de uma demonstração financeira é devida ao audit delay (Abbott et al., 2012).

A amostra direcionou os métodos estatísticos aplicados. Sobretudo pelo fato de o número de demonstrações e companhias auditadas na amostra ser reduzido, este estudo recorreu a testes nãoparamétricos em suas avaliações. Endossando essa decisão, parece haver padrão de não-normalidade das estatísticas de audit delay, com distribuição assimétrica positiva anteriormente reportada (e.g., Dyer IV \& McHugh, 1975; Davies \& Whittred, 1980; Whittred, 1980).

O primeiro teste promovido compara os resultados das distribuições acumuladas do $A D L$ em 2015 e 2016. De acordo com a hipótese proposta, são esperadas distribuições de $A D L$ distintas para as empresas que continham seções de PAA em 2016, em relação às distribuições da mesma subamostra para o ano anterior, i.e., 2015, quando não havia exigência de PAA. Para a subamostra das empresas que não publicaram os PAA, as distribuições para o ano de 2016 devem ser iguais às de 2015 . O teste utilizado é o KS, usualmente empregado na literatura contábil para julgar a normalidade da distribuição de uma variável aleatória. Aqui, comparam-se as distribuições acumuladas em um ano contra outro, para cada subamostra.

Formalmente, considera-se $A D L$ uma variável aleatória, sendo sua função de distribuição cumulativa $F(A D L)$ :

$$
F(A D L)=\mathrm{P}(A D L \leq a d l)
$$

em que adl é um conjunto de valores possíveis para $A D L$ e $F(A D L)$ é a probabilidade de $A D L$ assumir um valor menor ou igual a adl. A distribuição cumulativa empírica de uma amostra de $n$ observações pode ser representada como

$$
F_{n}(a d l)=P_{n}(A D L \leq a d l)=\frac{1}{n} \sum_{i=1}^{n} I\left(A D L_{i} \leq a d l\right)
$$

em que $I$ é um indicador que vale 1 quando $A D L_{i} \leq a d l$, e 0 caso contrário. A estatística do teste $K S$ de duas amostras $X$ e $Y$ (e.g., $X=2015$ e $Y=2016)$ é dada por

$$
K S_{X, Y}=\max _{\text {adl }}\left|F_{Y, n}(a d l)-F_{X, n}(a d l)\right|
$$

em que $K S_{X, Y}$ deve ser igual a zero se ambas as distribuições empíricas forem iguais. Nesse teste, as hipóteses nula e alternativa são construídas como:

$$
\begin{gathered}
H_{0}: F_{X}(a d l)=F_{Y}(a d l), \quad \forall \text { adl } \in D L, \\
H_{1}: F_{X}(a d l) \neq F_{Y}(a d l), \text { para algum adl } \in D L,
\end{gathered}
$$

Os valores calculados para a estatística $K S_{X, Y}$ são comparados com valores críticos obtidos em Gibbons e Chakraborti (2011) e corrigidos pelo algoritmo do software utilizado, o Stata 14. Para se confirmar a hipótese de pesquisa, no sentido de que a introdução do PAA aumentaria o audit delay, é esperada a rejeição de $H_{0}$ para a subamostra de empresas que publicaram os PAA, mas não rejeição para a subamostra daquelas que não publicaram a nova seção.

Além de observar as distribuições acumuladas antes e depois da divulgação da seção PAA e avaliar suas maiores diferenças para as subamostras construídas, a análise prossegue com o segundo teste deste estudo, focando diretamente na centralidade das distribuições. Como o audit delay de mesma companhia em dois anos subsequentes implica dependência ou pareamento das amostras, é empregado um teste de sinais nessa tarefa.ii

O teste empregado estabelece que a distribuição de uma variável aleatória $D$ tem mediana igual a zero e, para este trabalho, $D=A D L_{Y}-A D L_{X}$ representa a mediana da diferença das distribuições de duas amostras $X$ e $Y$. Da mesma maneira que no teste anterior, emprega-se o período que antecede a exigência de publicação de PAA, i.e., 2015, e o primeiro ano em que houve tal exigência, i.e., 2016. Assim, $X=2015$ e 
$Y=2016$. Como benefício de sua aplicação, o teste não faz pressuposição adicional sobre as distribuições. A estatística para o teste é o número $N_{+}$de diferenças $D$ maiores que zero. Supondo que a probabilidade de uma diferença $D$ seja igual a zero, então, sob a hipótese nula, $N_{+}$possui distribuição binomial com parâmetros $n$ e $p$, em que $n$ é o número total de observações e $p=1 / 2$, isto é, $H_{0}: N_{+} \sim \mathrm{b}(n=122, p=1 / 2)$, com hipótese alternativa de que $N_{+}$não possui distribuição binomial com os parâmetros $n$ e $p$. De maneira semelhante ao adotado com o teste KS, espera-se rejeição de $H_{0}$ para a subamostra de empresas que publicaram PAA em 2016, mas não rejeição para a subamostra daquelas que não publicaram a nova seção em 2016.

Apesar das restrições derivadas da amostra, como a imposição de graus de liberdade aquém daqueles usuais em trabalhos desta natureza, uma avaliação econométrica também foi considerada. Optouse por aplicar, como terceiro teste do estudo, o modelo de diferença-em-diferença (dif-in-dif) possível com os dados disponíveis para os dois períodos. Como benefício dessa modelagem, permite-se controlar fatores associados ao audit delay que não estão associados, por suposição, à apresentação da seção PAA nos relatórios do auditor independente, mas influenciam a $A D L$ e são tratados de maneira mais apropriada com um método multivariado.

Dentre as variáveis independentes, a de maior interesse recai sobre a introdução da seção PAA, ocorrida em 2016. Com o objetivo de capturar esse efeito, empregou-se o estimador de diferença-emdiferença $A N O^{\star} P A A$, variável de interação construída pela multiplicação de $A N O$ com $P A A$. Com base nessa variável e em outras descritas adiante, a equação a ser empregada na avaliação da hipótese de pesquisa pode ser escrita como:

$$
\ln \left(A D L_{i, t}\right)=\beta_{0}+\beta_{1} A N O_{t}+\beta_{2} P A A_{i}+\beta_{3}(A N O * P A A)_{i, t}+X^{\prime} \delta+\varepsilon_{i, t}
$$

em que a variável dependente $A D L$ é considerada em seu logaritmo natural; $A N O, P A A$ e $A N O^{\star} P A A$ são variáveis descritas anteriormente; $X^{\prime}$ é um vetor de variáveis explicativas de controle; $\delta$ é um vetor de parâmetros a ser estimado; $\varepsilon$ é o termo de erros aleatórios e os indexadores são para cada corporação auditada $i$ e ano $t$. $O$ parâmetro de interesse é $\circ \beta_{3}$, que deve possuir sinal positivo para corroborar a hipótese de pesquisa.

As estimações dos parâmetros das equações foram realizadas pelo método dos Mínimos Quadrados Ordinários, empilhando os dados (POLS), e também pelos estimadores de efeitos aleatórios (RE) e de efeitos fixos (FE) para dados em painel.

Dada a distribuição de empresas que emitiram PAA $(P A A=1)$ ser de entidades usualmente listadas na B3 e não pertencentes ao setor financeiro, um viés de seleção deve estar presente por construção. Para mitigar parte dos efeitos sobre a variável $A D L$ (audit delay) que estarão nos erros estimados, são empregadas as variáveis de controle comentadas a seguir e anteriormente descritas na Tabela 1.

A variável LNAT é usualmente associada ao tamanho da corporação auditada e apresenta resultados robustos em pesquisas anteriores (e.g., Dyer IV \& McHugh, 1975; Givoly \& Palmon, 1982; Ashton et al., 1987; $\mathrm{Ng} \&$ Tai, 1994), que induzem à expectativa de um parâmetro negativo para o parâmetro da variável, uma vez que empresas de maior porte tendem a possuir maiores e melhores sistemas de controle e acesso a recursos. Como estruturas de governança corporativa presentes e bem organizadas tendem a apresentar menor demora de auditoria (e.g., Abbott et al., 2012; Pizzini et al., 2015; Ramos \& Cunha, 2015), são esperados parâmetros com sinais negativos para as variáveis GC, IBOV e FIN, todas associadas a uma governança corporativa mais bem estabelecida e sob forte regulação, no caso das instituições financeiras. Quanto à qualificação da opinião, a literatura evidencia que relatórios limpos tendem a apresentar menor demora de auditoria (Pereira \& Costa, 2012). Assim, espera-se parâmetro negativo para a variável $O Q$.

Em relação à dummy BIG4, se por um lado o pertencimento a essa categoria pode reduzir os audit delays pelo fato de as firmas desse grupo possuírem maior estrutura tecnológica, operacional e staff para realizar auditorias em menor tempo (Newton \& Ashton, 1989; Ettredge, Li, \& Sun, 2006), é razoável conjecturar que as mesmas firmas possuem maior poder para incluir mais tópicos na seção PAA e, como consequência, retardar a assinatura do relatório de auditoria. Tal contra-argumento pode justificar os resultados apresentados por Durand (2018), que não encontrou significância em 29 dos 40 trabalhos analisados que incluíam variáveis dummy Big4, Big5 ou Big8 em estimações sobre o audit delay. A despeito dos efeitos contrários acima comentados, espera-se parâmetro negativo da dummy BIG4, significando um menor audit delay para entidades auditadas por firmas pertencentes ao grupo.

Para checar a presença potencial de multicolinearidade nas regressões, a análise econométrica é precedida por uma avaliação dos coeficientes de correlação de Pearson entre as variáveis empregadas, considerando sua equivalência à correlação ponto-bisserial. Dadas as características da amostra, usuais testes de normalidade das séries foram ignorados. Do mesmo modo, nenhum outlier foi retirado das avaliações uma vez que os atrasos, ou audit delay superior ao limite legal que caracterizam esses outliers, são de interesse da pesquisa. Por fim, o julgamento entre os modelos de efeito fixo (FE) ou aleatório (RE) foi realizado com a aplicação do teste de Hausman, com hipótese nula de que a diferença entre os 
coeficientes dos modelos não é sistemática e cuja rejeição se alinha favoravelmente ao modelo de efeitos fixos.

\section{Resultados}

A análise da hipótese de pesquisa proposta é iniciada com a apresentação da distribuição acumulada do audit delay, que mostra pequena variação entre as publicações de 2015 e 2016. O exame visual das frequências acumuladas do audit delay na Figura 2 evidencia os primeiros indícios de refutação da hipótese proposta para as publicações de demonstrações financeiras com seções de PAA nos relatórios de auditores independentes. Não somente o audit delay não aumentou para a subamostra de empresas que publicaram a seção PAA (Figura 2a), como aparentemente foi menor em 2016. A mesma conclusão parece aderente aos dados completos (Figura 2c). Para as empresas sem a nova seção (Figura 2b), os resultados sugerem a manutenção ou pequena ampliação do audit delay.

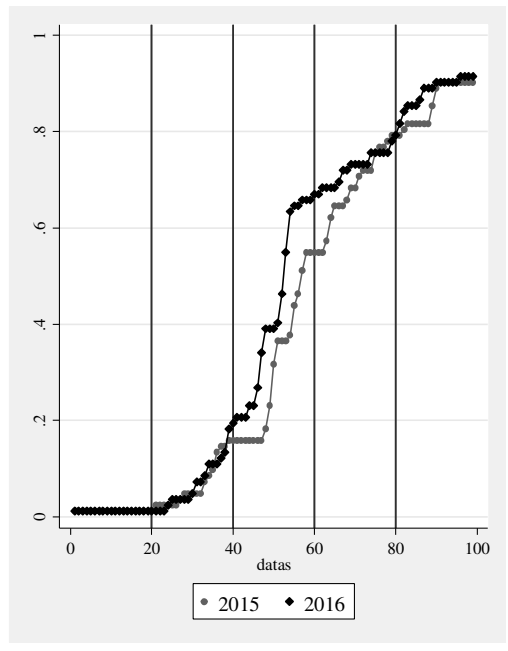

(a) Com PAA em 2016

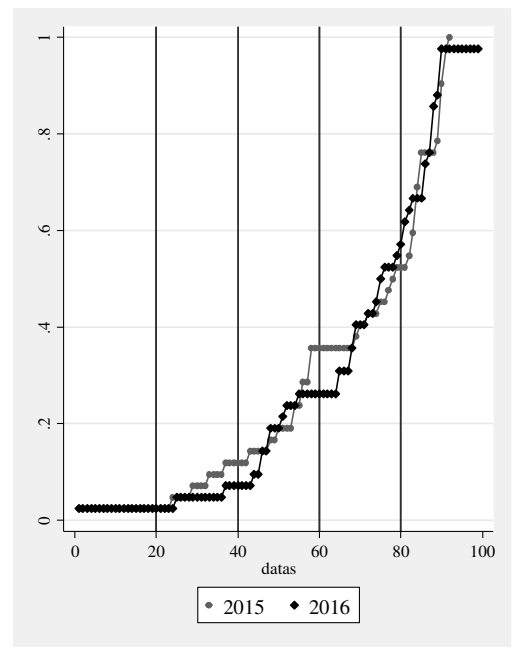

(b) Sem PAA em 2016

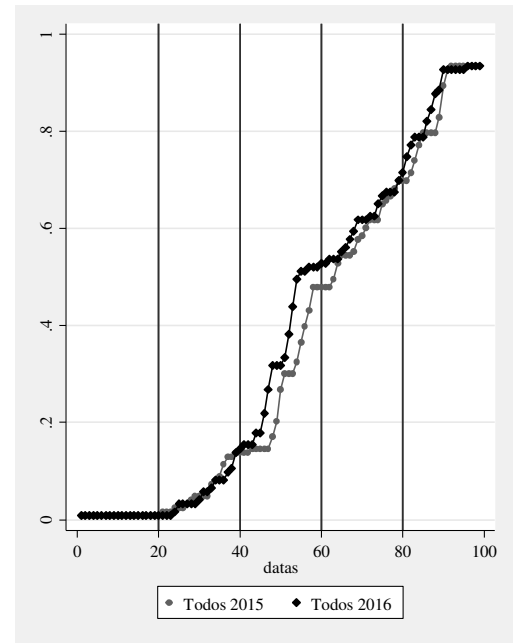

(c) Ambos os subgrupos

Figura 2 - Distribuição acumulada - $A D L$

Fonte: Elaborado pelos autores

Para avaliar a significância desses indícios verificados na análise gráfica foram realizados testes KS nas subamostras, cujos resultados são sintetizados na Tabela 4. Ao nível de significância de 10\%, os resultados dos testes KS rejeitaram a igualdade das distribuições acumuladas para a subamostra de empresas com PAA (valor-p de 0,008) e para a amostra total (valor-p de 0,054). Esses dados refutam a hipótese de pesquisa e, contrariamente, endossam a ideia de que a introdução do PAA se associou a um menor audit delay nas firmas de maneira significativa (ao nível de 10\%), sem mostrar diferença relevante nas empresas sem seção de PAA em seus relatórios.

Tabela 4

Resultados do teste Kolmogorov-Smirnov para subamostras

\begin{tabular}{lrrr}
\hline & Observações & Estatística KS & Valor-p (exato) \\
\hline Com PAA em 2016 & 81 & 0,2593 & 0,008 \\
Sem PAA em 2016 & 41 & 0,0976 & 0,991 \\
Ambos os subgrupos & 122 & 0,1721 & 0,054 \\
\hline
\end{tabular}

Hipótese nula para todas as linhas: $F_{2015}(\mathrm{adl})=F_{2016}(\mathrm{adl})$

Apesar de a análise apresentada parecer conclusiva, ela comparou as diferenças acumuladas do audit delay, mas não as centralidades das distribuições. Nessa tarefa, os valores médios das subamostras, apresentados na Tabela 5, são ilustrativos e endossam os resultados dos exames até aqui. Os dados da amostra revelaram queda no audit delay para o subgrupo que passou a apresentar seção PAA em 2016, mas aumento para o subgrupo que não apresentou PAA, passando de 71,2 para 75,6 dias. Como inferência especulativa, pode ter ocorrido deslocamento da força de trabalho, dentro das firmas de auditoria, dos trabalhos convencionais para aqueles em que o PAA foi requerido. Tal conjectura ficou menos evidente pela observação das medianas, que mostraram queda em 2016 para todos os subgrupos. De qualquer forma, a análise das medidas de tendência central reforça a perspectiva da análise gráfica e do teste KS no sentido de refutar a hipótese de pesquisa, ou seja, a incorporação da seção dos PAA no relatório de auditoria não provocou aumento do audit delay - ao contrário, há evidências no sentido inverso. 
Tabela 5

Estatísticas da variável $A D L$ para períodos e subamostras

\begin{tabular}{|c|c|c|c|c|c|c|c|c|c|}
\hline & \multirow[b]{2}{*}{ Obs } & \multicolumn{4}{|c|}{ Dias em 2015} & \multicolumn{4}{|c|}{ Dias em 2016} \\
\hline & & Média & Mediana & Min & Máx & Média & Mediana & Min & Máx \\
\hline Com PAA em 2016 & 81 & 97,88 & 57 & 21 & 814 & 75,09 & 53 & 24 & 656 \\
\hline Sem PAA em 2016 & 41 & 71,24 & 79 & 24 & 92 & 75,63 & 76 & 25 & 241 \\
\hline Ambos os subgrupos & 122 & 88,89 & 64 & 21 & 814 & 75,27 & 55 & 24 & 656 \\
\hline
\end{tabular}

Para o segundo teste, foi realizado o exame formal da mediana das diferenças entre os audit delay nos anos considerados com apoio do teste de sinais. Os resultados são apresentados na Tabela 6 e indicaram diferenças significativas no audit delay para a subamostra de empresas que apresentaram a seção de PAA ao nível de significância de $10 \%$ (estatística $D$ de 1,78) mas com sinal contrário ao esperado na formulação da hipótese de pesquisa. Todas as demais diferenças foram rejeitadas ao mesmo nível de significância ou melhor, isto é, não indicaram ter havido alteração significativa na mediana dos audit delays entre os períodos. Tomando esses resultados em conjunto, eles reforçam as evidências anteriores no sentido de não somente refutaram a hipótese de aumento do audit delay após a adoção dos PAA, como corroboraram a ocorrência de efeito contrário em alguns casos, isto é, redução do audit delay, aderente ao evidenciado para o caso francês (Bédard et al., 2019).

Tabela 6

Resultados do teste de sinais para subamostras

\begin{tabular}{lrrr} 
& Observações & Estatística D & Valor-p \\
\hline Com PAA em 2016 & 81 & 1,776 & 0,076 \\
Sem PAA em 2016 & 41 & 0,269 & 0,788 \\
Ambos os subgrupos & 122 & 1,331 & 0,183 \\
\hline
\end{tabular}

Hipótese nula para todas as linhas: $A D L_{2015}=A D L_{2016}$

Por fim, como as características das empresas auditadas e das firmas de auditoria potencialmente influenciam o audit delay, análises multivariadas são desejáveis. Assim, parte-se para o terceiro teste proposto por este estudo. A aplicação do modelo econométrico aqui adotado deve ser vista com cautela devido à micronumerosidade dos dados e provável quebra de hipóteses sobre distribuições conhecidas e bem comportadas, mas permite controle conveniente de variáveis independentes relevantes. Essa etapa de análise iniciou-se com a observação das correlações entre as variáveis consideradas.

Tabela 7

Correlação de Pearson entre pares de variáveis

\begin{tabular}{|c|c|c|c|c|c|c|c|c|c|}
\hline & $A D L$ & $P A A$ & ANO & LNAT & $G C$ & IBOV & FIN & $O Q$ & BIG4 \\
\hline$A D L$ & 1 & & & & & & & & \\
\hline$P A A$ & 0,065 & 1 & & & & & & & \\
\hline ANO & $-0,072$ & 0,000 & 1 & & & & & & \\
\hline LNAT & 0,014 & $0,240^{*}$ & 0,004 & 1 & & & & & \\
\hline$G C$ & $-0,018$ & $0,598^{*}$ & 0,000 & $0,141^{*}$ & 1 & & & & \\
\hline IBOV & $-0,007$ & $0,462^{*}$ & 0,000 & $0,359^{*}$ & $0,555^{*}$ & 1 & & & \\
\hline FIN & $-0,058$ & $-0,550^{*}$ & 0,000 & $-0,020$ & $-0,793^{*}$ & $-0,639^{*}$ & 1 & & \\
\hline$O Q$ & 0,074 & $-0,289^{*}$ & $-0,055$ & $-0,025$ & $-0,359^{*}$ & $-0,248^{*}$ & $0,320^{*}$ & 1 & \\
\hline BIG4 & $-0,043$ & $-0,131^{*}$ & 0,000 & $-0,117$ & $-0,170^{*}$ & $-0,245^{*}$ & $0,190^{*}$ & 0,061 & 1 \\
\hline
\end{tabular}

Legenda: * indica significância ao nível de $5 \%$

Os resultados apresentados na Tabela 7 demonstram, inicialmente, que isoladamente nenhuma das variáveis explicativas explica o comportamento do audit delay. Entre as variáveis independentes foi constatada forte correlação entre o par de variáveis $G C$ e $F I N$, igual a $-0,793$, sinalizando precaução em razão da ameaça de multicolinearidade nas avaliações econométricas. Em decorrência, foram gerados modelos alternativos avaliados sem as variáveis FIN (modelo 1) e GC (modelo 2).

Ainda em relação à correlação entre as variáveis independentes, e considerando o foco do estudo, chama a atenção o fato de a adoção da seção PAA ser: (i) diretamente associada com o tamanho das entidades (LNAT), o pertencimento aos segmentos de governança corporativa da B3 (GC) e o fato de integrarem o lbovespa (IBOV), coerente com as expectativas; (ii) inversamente associada com o segmento financeiro $(F I N)$ e as firmas de auditoria big four (B4), o que pode ser explicada pelo viés de seleção de entidades não listadas, que se concentrou em instituições financeiras, que são, por sua vez, quase que exclusivamente auditadas pelas principais firmas de auditoria, conforme evidenciado por Guimarães e Dantas (2015); e (iii) associação negativa com a incidência de opinião qualificada $(O Q)$ no relatório de auditoria, sugerindo que a adoção da seção dos PAA pode ter influenciado a incidência de modificação de opinião no relatório de auditoria. Essa última evidência sugere a conveniência de estudo que explore essa relação com mais profundidade, no sentido de confirmar os eventuais impactos da adoção dos PAA no tipo de opinião emitido pelos auditores. 
Subsequentemente à avaliação das correlações, para a realização da análise multivariada foram estimadas duas versões do modelo base - usando, alternadamente, as variáveis independentes FIN e GC, dado o risco de multicolinearidade -, utilizando os métodos com dados empilhados (POLS) e dados em painel com efeitos fixos (FE) e com efeitos aleatórios (RE). Os resultados dessa combinação de testes são sintetizados na Tabela 8.

Tendo por base os resultados em relação à variável de interesse $\left(P P A^{*} A N O\right)$, as análises econométricas demonstraram, com razoável consistência, o efeito contrário ao esperado pela hipótese de pesquisa em razão da introdução da seção PAA. Em quatro das seis estimações foi encontrada associação negativa entre a variável de interesse e a variável dependente, quando a hipótese de pesquisa previa associação positiva. Assim, de maneira semelhante ao apontado pela análise gráfica, Testes KS e comparação das estatísticas de tendência central, as regressões mostraram uma redução do audit delay com a adoção da nova seção.

Apesar da ausência de outras variáveis no modelo econométrico, no entanto, os resultados das estimações se alinharam às conclusões precedentes de maneira convincente. $O$ estimador de diferençasem-diferenças representado pela variável de interação $A N O^{*} P A A$ mostrou sinais negativos, sendo significativos ao nível de $10 \%$ em quase todos os modelos testados, exceto para as estimações com dados empilhados, que sofrem do conhecido viés de variável omitida (Henderson \& Kaplan, 2000). Dentre os modelos de painel, os de efeitos aleatórios são preferidos pelos resultados obtidos nos testes de Hausman (resultados não apresentados).

Tabela 8

Principais resultados das estimações [variável dependente: $\ln (A D L)$ ]

\begin{tabular}{|c|c|c|c|c|c|c|}
\hline Variáveis & POLS (1) & FE (1) & $\operatorname{RE}(1)$ & POLS (2) & FE (2) & $\mathrm{RE}(2)$ \\
\hline \multirow[t]{2}{*}{$P A A$} & 0,0524 & $-0,927$ & 0,0432 & $-0,0347$ & 0,123 & $-0,0496$ \\
\hline & $(0,124)$ & $(0,618)$ & $(0,133)$ & $(0,115)$ & $(0,364)$ & $(0,128)$ \\
\hline \multirow[t]{2}{*}{ ANO } & 0,0537 & 0,0492 & 0,0502 & 0,0560 & 0,0492 & 0,0516 \\
\hline & $(0,0773)$ & $(0,0597)$ & $(0,0595)$ & $(0,0792)$ & $(0,0597)$ & $(0,0595)$ \\
\hline \multirow[t]{2}{*}{$A N O^{\star} P A A$} & $-0,176$ & $-0,182^{\star \star}$ & $-0,175^{\star \star}$ & $-0,178$ & $-0,182^{\star \star}$ & $-0,176^{\star *}$ \\
\hline & $(0,126)$ & $(0,0731)$ & $(0,0727)$ & $(0,125)$ & $(0,0731)$ & $(0,0727)$ \\
\hline \multirow[t]{2}{*}{ LNAT } & $-0,00801$ & 0,253 & $-0,00125$ & 0,0164 & 0,253 & 0,0226 \\
\hline & $(0,0224)$ & $(0,212)$ & $(0,0349)$ & $(0,0237)$ & $(0,212)$ & $(0,0363)$ \\
\hline \multirow[t]{2}{*}{$G C$} & 0,0152 & $1,050^{* *}$ & 0,00654 & & & \\
\hline & $(0,120)$ & $(0,412)$ & $(0,131)$ & & & \\
\hline \multirow[t]{2}{*}{ FIN } & & & & $-0,274^{\star *}$ & $-0,249$ & $-0,271^{*}$ \\
\hline & & & & $(0,113)$ & $(0,458)$ & $(0,139)$ \\
\hline \multirow[t]{2}{*}{ IBOV } & $-0,0576$ & $-0,766^{\star \star}$ & $-0,0676$ & $-0,209^{*}$ & $-1,015^{\star \star \star}$ & $-0,222$ \\
\hline & $(0,109)$ & $(0,293)$ & $(0,128)$ & $(0,116)$ & $(0,367)$ & $(0,142)$ \\
\hline \multirow[t]{2}{*}{$O Q$} & 0,158 & $-0,0161$ & 0,0830 & 0,197 & $-0,0161$ & 0,104 \\
\hline & $(0,128)$ & $(0,158)$ & $(0,120)$ & $(0,129)$ & $(0,158)$ & $(0,119)$ \\
\hline \multirow[t]{2}{*}{ BIG4 } & $-0,0743$ & 0,263 & $-0,0738$ & $-0,0466$ & 0,263 & $-0,0460$ \\
\hline & $(0,289)$ & $(0,332)$ & $(0,273)$ & $(0,285)$ & $(0,332)$ & $(0,269)$ \\
\hline \multirow[t]{2}{*}{ CONSTANTE } & $4,384^{\star \star \star}$ & $-0,0156$ & $4,293^{\star \star *}$ & $4,207^{\star \star \star}$ & $-0,0156$ & $4,126^{\star \star \star}$ \\
\hline & $(0,437)$ & $(3,547)$ & $(0,644)$ & $(0,410)$ & $(3,547)$ & $(0,633)$ \\
\hline 'Observações & 244 & 244 & 244 & 244 & 244 & 244 \\
\hline Prob $>F^{3} \#$ & 0,025 & 0,032 & 0,184 & 0,081 & 0,030 & 0,056 \\
\hline $\mathrm{R}^{2}$ & 0,025 & 0,086 & 0,073 & 0,052 & 0,086 & 0,074 \\
\hline $\mathrm{N}$ & 122 & 122 & 122 & 122 & 122 & 122 \\
\hline
\end{tabular}

Em relação às variáveis de controle, os testes revelaram que, de forma geral, o audit delay é negativamente relacionado às variáveis IBOV e $F I N$, indicando que entidades listadas em bolsa de valores ou pertencentes ao setor financeiro apresentaram menor audit delay do que as não listadas ou de outros setores econômicos. Em conjunto com a significância do parâmetro da variável de interação, o resultado da variável FIN sugere haver pequeno risco de aumento no audit delay de instituições financeiras com a exigência de publicação de seção PAA em relatórios de auditoria a partir de 2020.

Adicionalmente, os testes empíricos demonstraram que o audit delay não tem relação com o tamanho das entidades ( $L N A T)$, com a emissão de opinião qualificada $(O Q)$ no relatório de auditoria, com o fato de a firma de auditoria ser uma das big four (BIG4) ou com o atendimento aos níveis do governança corporativa da B3 (GC).

Os resultados possuem deficiências esperadas. As estatísticas $F$, apesar de relevantes ao nível de significância usual de 10\%, seriam rejeitadas a níveis mais exigentes. Para o modelo de efeitos aleatórios com a variável $G C$ [i.e., $R E(1)$ ], não se rejeita a nulidade de todos os coeficientes ao nível usual de $10 \%$, ou 
melhor. Aderente à carência comentada, o poder explicativo de cada modelo, medido pelos coeficientes de determinação $\left(R^{2}\right)$ das estimações, foram baixos, com valores variando próximos de uma média de $7 \%$ nos modelos considerados e nunca superior a $9 \%$. A presença de muitas dummies nas regressões, dada pela ausência de outras variáveis disponíveis, certamente contribuiu para a existência dos pontos fracos comentados sobre as análises econométricas. Por escolha ad hoc dos autores, preferiu-se a realização das regressões por servirem como apoio aos resultados obtidos nas avaliações univariadas, a despeito das deficiências existentes.

Em resumo, os resultados parecem conclusivos em indicar que não houve aumento no audit delay no primeiro ano de publicação da seção PAA. Como comentado anteriormente, se alinham qualitativamente ao encontrado para o caso francês (Bédard et al., 2019). Se parece extremado utilizar os resultados quantitativos para inferir que não houve incremento nos custos de produção do serviço de auditoria, como em Mello et al. (2021), prefere-se, aqui, reforçar que pode ter ocorrido deslocamento da força de trabalho, dentro das firmas de auditoria, dos trabalhos convencionais em direção aqueles em que o PAA foi requerido, o que explicaria o resultado encontrado. De qualquer modo, fica evidente a necessidade de se incorporar outros elementos de análise para se concluir definitivamente sobre o tema.

\section{Conclusão}

Desde a promulgação da lei Sarbanes-Oxely, mas especialmente com o encurtamento do prazo exigido para envio de relatórios financeiros, estabelecido nos EUA em 2006, há pressão crescente sobre firmas de auditoria e auditores independentes para a entrega de seus relatórios de asseguração em prazos cada vez menores. Exercendo força propulsora nesse processo, a incorporação de novos mecanismos inovativos como o uso de inteligência artificial nos serviços de auditoria deve, possivelmente, impor aos profissionais envolvidos maior cobrança por entregas tempestivas.

Nesse contexto, a criação da seção PAA no relatório dos auditores independentes implicaria no risco de, ao criar uma nova exigência aos auditores, ampliar o tempo necessário à finalização do relatório de asseguração e, consequentemente, à publicação das demonstrações financeiras. Se outros autores investigaram os efeitos das exigências trazidas com a nova seção sobre aspectos de qualidade dos relatórios dos auditores no Brasil (e.g., Cruz, Nardi, Figueira, \& Silva, 2019; Camargo et al., 2019), este estudo avaliou os efeitos sobre um dos principais determinantes do tempo de entrega das demonstrações financeiras, o audit delay.

Adicionalmente, a exigência de comunicação dos PAA nos relatórios da auditoria independente nas demonstrações de algumas instituições financeiras a partir de 2020, em decorrência da Resolução CMN $n^{\circ}$ 4.720 , de 2019, gerou receio sobre aumento no tempo para publicação dessas instituições, que compõem setor importante na economia nacional. Motivado por essa preocupação, este trabalho avaliou a hipótese de que a criação da seção PAA estaria associada com um aumento no audit delay. Por isso, observou-se a existência de alterações no audit delay em 2016, primeiro ano de exigência de publicação da nova seção para empresas abertas, como insumo para se avaliar impactos prováveis nas demonstrações de instituições financeiras em 2020.

Os resultados do estudo se mostraram aderentes ao documentado para o caso francês (Bédard et al., 2019), em que o surgimento da nova seção foi associado a uma redução no audit delay, em oposição ao efeito adverso proposto pela hipótese de pesquisa. Sob outro ponto de vista, os resultados dos casos francês e brasileiro estão alinhados à ideia de que os auditores, ao realizarem assegurações razoáveis das demonstrações financeiras, finalizaram seus processos tempestivamente mesmo após o surgimento do PAA, de maneira a gerar maior utilidade para os usuários das demonstrações asseguradas.

Assim, em resposta ao receio atribuído à exigência de inclusão da seção PAA nos relatórios de auditoria de instituições financeiras, a partir de 2020, a significância consistente de menor audit delay para as empresas do setor financeiro consolida a percepção de baixo risco de atrasos como consequência da referida norma. ${ }^{\text {iv }}$

Este estudo também revelou que o conhecimento da literatura sobre o tema audit delay está incompleto. Avaliações quantitativas como a realizada neste trabalho apresentam, de maneira contumaz, baixos coeficientes de determinação e, não raramente, só abordam um dos lados que constituem o mercado de auditoria: a oferta pelas firmas de auditoria, ou a demanda pelas entidades auditadas. Fora do esquadro quantitativo, avaliações qualitativas poderiam agregar na contemplação da negociação final entre a firma de auditoria e a corporação auditada, que precede a finalização da atividade e é parte essencial de toda a atividade de asseguração.

Observando criticamente as análises quantitativas realizadas, uma resposta definitiva ao problema proposto exige a incorporação de novas variáveis que reflitam mais diretamente outros elementos da complexidade da entidade auditada e do risco do cliente, como sugerido por Simunic (1984).

Do lado da entidade auditada, controles pouco estruturados ou sistemas deficientes, cujos efeitos sobre o audit delay não são capturados pelas variáveis LNAT ou GC, poderiam gerar maior dificuldade para o processo de auditoria e, consequentemente, influenciar o $A D L$. Fintechs com tecnologia integrada à prestação dos serviços oferecidos, por exemplo, podem possuir processamento e realização de atividade de 
auditoria mais célere, apesar dessas empresas possuírem, possivelmente, menor ativo ou governança corporativa menos estruturada que as incumbentes estabelecidas. Nessa linha, outras variáveis que medissem a qualidade dos controles ou a complexidade da entidade auditada, poderiam agregar na mensuração das variações do $A D L$.

Do lado da firma de auditoria, maior esforço ou volume de trabalho despendido pode estar relacionado à menor $A D L$, que não parece ter sido capturado pelas variáveis empregadas no estudo. Se uma proxy adequada poderia ser construída para medir os insumos em cada engagement, o número de horas alocadas e a proporção de senioridade do time alocado são informações calculadas pelas firmas de auditoria (Knechel \& Payne, 2001). Apesar de o acesso a essas informações ser restrito, seu uso poderia contribuir para uma melhor compreensão dos determinantes do audit delay e o real impacto da introdução da seção PAA sobre o mercado.

Os resultados opostos nos audit delays observados para as subamostras de empresas com e sem PAA sugeriram a conjectura de deslocamento da força de trabalho dentro das firmas de auditoria em direção aos trabalhos em que a nova seção era requerida. Apesar de especulativo, esse poderia ser um caminho possível para pesquisas futuras, mas cuja resposta definitiva depende da obtenção de informações adicionais.

\section{Referências}

Abbott, L. J., Parker, S., \& Peters, G. F. (2012). Internal audit assistance and external audit timeliness. Auditing: A Journal of Practice \& Theory, 34(4), 3-20. https://doi.org/10.2308/ajpt-10296

Abernathy, J. L., Barnes, M., Stefaniak, C., \& Weisbarth, A. (2017). An international perspective on audit report lag: a synthesis of the literature and opportunities for future research. International Journal of Auditing, 21(1), 100-127. https://doi.org/10.1111/ijau.12083

Alves, E. D., \& Galdi, F. C. (2020). Relevância informacional dos principais assuntos de auditoria. Revista Contabilidade \& Finanças, 31(82), 67-83. https://doi.org/10.1590/1808-057x201908910

Ashton, R. H., Willingham, J. J., \& Elliott, R. K. (1987). An empirical analysis of audit delay. Journal of Accounting Research, 25(2), 275-292. https://doi.org/10.2307/2491018

Bédard, J., Gonthier-Besacier, N., \& Schatt, A. (2019). Consequences of expanded audit reports: Evidence from the justifications of assessments in France. Auditing: A Journal of Practice \& Theory, 38(3), 23-45. https://doi.org/10.2308/ajpt-52339

Begley, J., \& Fischer, P. E. (1998). Is there information in an earnings announcement delay? Review of Accounting Studies, 3(4), 347-363. https://doi.org/10.1023/A:1009635117801

Blankley, A. I., Hurtt, D. N., \& MacGregor, J. E. (2015). Are lengthy audit report lags a warning signal? Current Issues in Auditing, 9(2), 19-28. https://doi.org/10.2308/ciia-51215

Bonsón-Ponte, E., Escobar-Rodríguez, T., \& Borrero-Domínguez, C. (2008). Empirical analysis of delays in the signing of audit reports in Spain. International Journal of Auditing, 12(1), 129-140.

https://doi.org/10.1111/j.1099-1123.2008.00375.x

Brasel, K., Doxey, M. M., Grenier, J. H., \& Reffett, A. (2016). Risk disclosure preceding negative outcomes: The effects of reporting critical audit matters on judgments of auditor liability. Current Issues in Auditing, 10(2),1-10. https://doi.org/10.2308/accr-51380

Braunbeck, G. O. (2010). Determinantes da qualidade das auditorias independentes no Brasil. Tese de Doutorado, Universidade de São Paulo, Faculdade de Economia, Administração e Contabilidade, São Paulo, Brasil. Disponível em https://teses.usp.br/teses/disponiveis/12/12136/tde-04112010-161444/pt-br.php

Bryant-Kutcher, L., Peng, E. Y., \& Weber, D. P. (2013). Regulating the timing of disclosure: Insights from the acceleration of 10-K filing deadlines. Journal of Accounting and Public Policy, 32(6), 475-494. https://doi.org/10.1016/j.jaccpubpol.2013.08.003

Camargo, N. S., Rodrigues, F. F., Machado, C. A., \& Guerra, M. (2019). Principais assuntos de auditoria e os resultados das empresas listadas na IBRX 100. Revista Contemporânea de Contabilidade, 16(41), 162180. http://dx.doi.org/10.5007/2175-8069.2019v16n41p162 
Christensen, B. E., Glover, S. M., \& Wolfe, C. J. (2014). Do critical audit matter paragraphs in the audit report change nonprofessional investors' decision to invest? Auditing: A Journal of Practice \& Theory, 33(4), 71-93. https://doi.org/10.2308/ajpt-50793

Comissão de Valores Mobiliários. (2017). Instrução CVM no 591. Disponível em:

http://www.cvm.gov.br/legislacao/instrucoes/inst591.html. Acesso em: 10 de janeiro de 2020.

Comissão de Valores Mobiliários. (2019). Ofício-Circular CVM/SNC/GNA/no01/2019. Disponível em: http://www.cvm.gov.br/legislacao/oficios-circulares/snc/oc-snc-gna-0119.html. Acesso em 10 de janeiro de 2020.

Conselho Federal de Contabilidade. (2016). Norma Brasileira de Contabilidade NBC TA 701 - Comunicação dos principais assuntos de auditoria no relatório do auditor independente. Disponível em:

https://www1.cfc.org.br/sisweb/SRE/docs/NBCTA701.pdf. Acesso em 10 de janeiro de 2020.

Conselho Monetário Nacional. (2019). Resolução n 4.720. Disponível em

https://www.bcb.gov.br/pre/normativos/busca/downloadNormativo.asp?arquivo=/Lists/Normativos/Attachmen $\underline{\text { ts/50768/Res } 4720 \text { v1 O.pdf }}$

Copley, P. A., Gaver, J. J., \& Gaver, K. M. (1995). Simultaneous estimation of the supply and demand of differentiated audits: Evidence from the municipal audit market. Journal of Accounting Research, 33(1), 137155. https://www.jstor.org/stable/2491296

Cordoş, G. S., \& Fülöp, M. T. (2015). Understanding audit reporting changes: Introduction of key audit matters. Accounting and Management Information Systems, 14(1), 128-152. Disponível em: http://onlinecig.ase.ro/jcig/art/14 1 6.pdf. Acesso em 10 de setembro de 2020.

Cruz, A. F., Nardi, P. C. C., Figueira, L. M., \& Silva, R. L. M. (2019). A relação entre o novo relatório do auditor independente e o perfil das empresas auditadas e de auditoria. Revista Contemporânea de Contabilidade, 16(40), 3-23. https://doi.org/10.5007/2175-8069.2019v16n40p3

Davies, B., \& Whittred, G. P. (1980). The association between selected corporate attributes and timeliness in corporate reporting: Further analysis. Abacus, 16(1), 48-60. https://doi.org/10.1111/j.1467-

6281.1980.tb00085.x

Durand, G. (2018). The determinants of audit report lag: a meta-analysis. Managerial Auditing Journal, 34(1), 44-75. https://doi.org/10.1108/MAJ-06-2017-1572

Dye, R. A. (1993). Auditing standards, legal liability, and auditor wealth. Journal of Political Economy, 101(5), 887-914. https://doi.org/10.1086/261908

Dyer IV, J. C., \& McHugh, A. J. (1975). The timeliness of the Australian annual report. Journal of Accounting Research, 13(2), 204-219. https://doi.org/10.2307/2490361

Ettredge, M.L., Li, C., \& Sun, L. (2006). The impact of SOX section 404 internal quality control assessment on audit delay in the SOX era. Auditing: A Journal of Practice \& Theory, 25(2), 1-23.

https://doi.org/10.2308/aud.2006.25.2.1

Gibbons, J. D., \& Chakraborti, S. (2011). Nonparametric statistical inference. 5를 ed. Boca Raton: Chapman \& Hall.

Gimbar, C., Hansen, B., \& Ozlanski, M. E. (2016). Early evidence on the effects of critical audit matters on auditor liability. Current Issues in Auditing, 10(1), 24-33. https://doi.org/10.2308/ciia-51369

Givoly, D., \& Palmon, D. (1982). Timeliness of annual earnings announcements: Some empirical evidence. The Accounting Review, 57(3), 486-508. https://www.jstor.org/stable/246875?seq=1

Guimarães, F. G., \& Dantas, J. A. (2015). Concentração do mercado de auditoria na indústria bancária brasileira. Revista Evidenciação Contábil \& Finanças, 3(3), 84-103. https://doi.org/10.18405/recfin20150306

Haut Conseil du commissariat aux comptes. (2006). Norme d'exercice professionnel "justification des appréciations", Paris. Disponível em http://www.h3c.org/fiches/nepjusti141006.htm. Acesso em 14 de outubro de 2020. 
Haw, I. M., Qi, D., \& Wu, W. (2000). Timeliness of annual report releases and market reaction to earnings announcements in an emerging capital market: The case of China. Journal of International Financial Management and Accounting, 11(2), 108-131. https://doi.org/10.1111/1467-646X.00058

Henderson, B. C., \& Kaplan, S. E. (2000). An examination of audit report lag for banks: A panel data approach. Auditing: A Journal of Practice \& Theory, 19(2), 159-174. https://doi.org/10.2308/aud.2000.19.2.159

Khoufi, N., \& Khoufi, W. (2018). An empirical examination of the determinants of audit report delay in France. Managerial Auditing Journal, 33(8/9), 700-714. https://doi.org/10.1108/MAJ-02-2017-1518

Kinney Jr., W. R., \& McDaniel, L. S. (1993). Audit delay for firms correcting quarterly earnings. Auditing: A Journal of Practice \& Theory, 12(2), 135-142.

Kiss, C., Fülöp, M. T., \& Cordoș, S. (2015). Relevant aspects regarding the changes of the statutory audit report in the light of international regulations. Audit financiar, 13(126), 63-73.

http://revista.cafr.ro/ArticolEN.aspx?CodArticol=9415

Knechel, W. R., \& Payne, J. (2001). Additional evidence on audit report lag. Auditing: A Journal of Practice \& Theory, 20(1), 137-146. https://doi.org/10.2308/aud.2001.20.1.137

Lawrence, E. C. (1983). Reporting delays for failed firms. Journal of Accounting Research, 21(2), 606-610. https://doi.org/10.2307/2490794

Marques, V. A., \& Souza, M. K. P. (2017). Principais assuntos de auditoria e opinião sobre o risco de descontinuidade: uma análise das empresas do lbovespa. Revista de Informação Contábil, 11(4), 1-22. https://periodicos.ufpe.br/revistas/ricontabeis/article/view/230107

Mello, L. C. O., Araújo, O. G. L., \& Luca, M. M. M. (2021). Impacto do novo relatório dos auditores independentes nos honorários dos auditores. Revista Contabilidade Vista \& Revista, 32(1), 183-217. https://doi.org/10.22561/cvr.v32i1.5952

Newton, J. D., \& Ashton, R. H. (1989). The association between audit technology and audit delay. Auditing: A Journal of Practice and Theory, 8(supplement), 22-37.

Ng, P. P. H., \& Tai, B. Y. K. (1994). An empirical examination of the determinants of audit delay in Hong Kong. The British Accounting Review, 26(1), 43-59. https://doi.org/10.1006/bare.1994.1005

Pereira, A. N., \& Costa, F. M. (2012). Determinantes do atraso de auditoria externa (audit delay) em companhias brasileiras. In: Encontro da ANPAD, 36., Rio de Janeiro. Anais [...] São Paulo: Associação Nacional de Pós-Graduação e Pesquisa em Administração. Disponível em: http://legado.fucape.br/ public/producao cientifica/2/ANTONIO.pdf. Acesso em 10 de setembro de 2020.

Pizzini, M., Lin, S., \& Ziegenfuss, D. E. (2015). The Impact of internal audit function quality and contribution on audit delay. Auditing: A Journal of Practice \& Theory, 34(1), 25-58. https://doi.org/10.2308/ajpt-50848

Public Company Accounting Oversight Board. (2013). PCAOB Release No. 2013-005, Washington - DC. Disponível em https://pcaobus.org/Rulemaking/Docket034/Release 2013-005 ARM.pdf. Acesso em 19 de setembro de 2019.

Public Company Accounting Oversight Board. (2017). PCAOB Release No. 2017-001, Washington - DC. Disponível em: https://pcaobus.org/Rulemaking/Docket034/2017-001-auditors-report-final-rule.pdf. Acesso em 19 de setembro de 2019.

Ramos, F., \& Cunha, P. (2015). Influência do rodízio de auditoria no audit delay das companhias brasileiras listadas na BM\&FBovespa. Anais do International Conference on Information Systems \& Technology Management - Contecsi, 12․ São Paulo. Disponível em:

http://www.contecsi.tecsi.org/index.php/contecsi/12CONTECSI/paper/view/3079. Acesso em 10 de setembro de 2020. 
Reid, L. C., Carcello, J. V., Li, C., \& Neal, T. L. (2019). Impact of auditor and audit committee report changes on audit quality and costs: Evidence from the United Kingdom. Contemporary Accounting Research, 36(3), 1501-1539. https://doi.org/10.1111/1911-3846.12486

Santana, L. R., Silva, F. J., Dantas, J. A., \& Botelho, D. R. (2019). Auditoria em bancos: relação entre os assuntos citados em modificação de opinião, ênfase e PAA. Revista Catarinense da Ciência Contábil, 18(1), 1-18. http://dx.doi.org/10.16930/2237-766220192832

Silva, P. S., Bianchi, M., \& Venturini, L. D. B. (2018). Principais assuntos de auditoria: Uma análise dos itens do relatório do auditor independente nos anos de 2016 e 2017. In: Congresso de Contabilidade da UFRGS, 3. Porto Alegre. Anais [...] Porto Alegre: Universidade Federal do Rio Grande do Sul. Disponível em: https://www.ufrgs.br/congressocont/index.php/IIIContUFRGS/IIIContUFRGS/paper/download/97/63. Acesso em 10 setembro de 2020 .

Simunic, D. (1984). Auditing, consulting, and auditor independence. Journal of Accounting Research, 22(1), 679-702. https://doi.org/10.2307/2490671

Sirois, L-P., Bédard, J., Bera, P. (2014). The informational value of key audit matters in the auditor's report: Evidence from an eye-tracking study. Accounting Horizons, 32(2), 141-162. https://doi.org/10.2308/acch$\underline{52047}$

Whittred, G. (1980). Audit qualification and the timeliness of corporate annual reports. The Accounting Review, 55(4), 563-577. http://www.jstor.org/stable/245775

* Uma versão preprint do artigo foi apresentada no XX USP International Conference on Accounting, 2020.

Apêndice

Lista de entidades incluídas na análise

\begin{tabular}{|c|c|c|}
\hline ABC Brasil & Bradesco & JBS \\
\hline Ambev & Bradespar & Klabin \\
\hline Azul & Braskem & Localiza \\
\hline $\mathrm{B} 2 \mathrm{~W}$ & BRB & Lojas Americanas \\
\hline B3 & BRFoods & Lojas Renner \\
\hline Banco Alfa & brMalls & Magazines Luiza \\
\hline Banco Caterpillar & BTG & Marfrig \\
\hline Banco CCB & CBD - Pão de Açucar & Metalúrgica Gerdau \\
\hline Banco CNH Industrial & CCR & MRV \\
\hline Banco da Amazônia & CEF & Multiplan \\
\hline Banco de Desenv Extremo Sul & Cemig & Natura \\
\hline Banco de Desenv. de MG & Cielo & Original \\
\hline Banco De Lage Landen DLL & Citibank & Paraná Banco \\
\hline Banco do Brasil & Cogna & Petrobrás \\
\hline Banco do Estado de SE & Cosan & Petrobrás Distribuidora \\
\hline Banco do Estado do PA & Crédit Agricole & Pine \\
\hline Banco do Nordeste & Credit Suisse & Qualicorp \\
\hline Banco Fibra & CSN & Rabobank \\
\hline Banco Fidis & CVC & Raia-Drogasil \\
\hline Banco GMAC & Cyrela & Rumo \\
\hline Banco Haitong & Daycoval & Sabesp \\
\hline Banco Honda & Deutsche Bank & Safra \\
\hline Banco IBM & EcoRodovias & Santander Brasil \\
\hline Banco Mercantil do Brasil & Eletrobrás & Scotiabank \\
\hline Banco Mercedes Benz & Embraer & Sicredi \\
\hline Banco Mizuho & Energias & Smiles \\
\hline Banco Modal & Engie & Société Genérale \\
\hline Banco PAN & Equatorial & Socopa \\
\hline Banco Sumitomo Mitsui & Fleury & Sofisa \\
\hline Banco Tokyo-Mitsubishi MUFG & Gerdau & Suzano \\
\hline Banco Toyota Brasil & Gol & Taesa \\
\hline
\end{tabular}




\begin{tabular}{lll}
\hline Banco Triangulo & Goldman Sachs & Telefônica Brasil \\
\hline Banco Volkswagen & Hypera & TIM Participações \\
\hline Bancoob & Iguatemi & Ultrapar \\
\hline Banestes & Industrial do Brasil & Usiminas \\
\hline Banrisul & Indusval & Vale \\
\hline BBSeguridade & Intermédica & Via Varejo \\
\hline BMG & Intermedium & Votorantim \\
\hline BNDES & IRBBrasil & WEG \\
\hline BNP Paribas & Itausa & YDUQS \\
\hline BOCOM BBM & ItaúUnibanco & \\
\hline
\end{tabular}

\section{NOTAS}

\section{AGRADECIMENTOS}

Os autores agradecem a contribuição de Jéssica Almino de Abreu na coleta de dados e os comentários dos pareceristas da Revista Contemporânea de Contabilidade e da XX Conferência Internacional de Contabilidade da USP, onde uma versão anterior do artigo foi apresentada. Todas as opiniões expressas são dos autores e não refletem, necessariamente, as de qualquer instituição.

\section{CONTRIBUIÇÃO DE AUTORIA}

Concepção e elaboração do manuscrito: C. T. Kawamoto, J. A. Dantas, J. R. M. Antiqueira

Coleta de dados: C. T. Kawamoto

Análise de dados: C. T. Kawamoto, J. A. Dantas, J. R. M. Antiqueira

Discussão dos resultados: C. T. Kawamoto, J. A. Dantas, J. R. M. Antiqueira

Revisão e aprovação: C. T. Kawamoto, J. A. Dantas, J. R. M. Antiqueira

\section{CONJUNTO DE DADOS DE PESQUISA}

O conjunto de dados que dá suporte aos resultados deste estudo está disponível publicamente.

\section{FINANCIAMENTO}

Não se aplica.

\section{CONSENTIMENTO DE USO DE IMAGEM}

Não se aplica.

\section{APROVAÇÃO DE COMITÊ DE ÉTICA EM PESQUISA \\ Não se aplica.}

\section{CONFLITO DE INTERESSES}

Não se aplica.

\section{LICENÇA DE USO}

Os Direitos Autorais para artigos publicados neste periódico são do autor, com direitos de primeira publicação para a Revista. Em virtude de aparecerem nesta Revista de acesso público, os artigos são de uso gratuito, com atribuições próprias, em aplicações educacionais, de exercício profissional e para gestão pública. A Revista adotou a licença Creative Commons Atribuição 4.0 Internacional - CC BY NC ND. Esta licença permite acessar, baixar (download), copiar, imprimir, compartilhar, reutilizar e distribuir os artigos desde que com a citação da fonte, atribuindo os devidos créditos de autoria. Nesses casos, nenhuma permissão é necessária por parte dos autores ou dos editores. Autores têm autorização para assumir contratos adicionais separadamente, para distribuição não-exclusiva da versão do trabalho publicada nesta revista (ex.: publicar em repositório institucional ou um capítulo de livro).

\section{PUBLISHER}

Universidade Federal de Santa Catarina. Curso de Ciências Contábeis e Programa de Pós-graduação em Contabilidade. Publicação no Portal de Periódicos UFSC. As ideias expressadas neste artigo são de responsabilidade de seus autores, não representando, necessariamente, a opinião dos editores ou da universidade.

\section{EDITORES}

Carlos Eduardo Facin Lavarda e Suliani Rover 


\section{HISTÓRICO}

Recebido em: 23/11/2020 - Revisado por pares em: 17/05/2021 - Reformulado em: 05/07/2021 Recomendado para publicação em: 21/07/2021 - Publicado em: 04/12/2021

\footnotetext{
${ }^{i}$ No Brasil, as normas que marcaram a chamada nova estrutura para o relatório de auditoria são a NBC TA 260 (R2) Comunicação com os Responsáveis pela Governança; NBC TA 570 - Continuidade Operacional; NBC TA 700 Formação da Opinião e Emissão do Relatório do Auditor Independente sobre as Demonstrações Contábeis; NBC TA 701 - Comunicação dos Principais Assuntos de Auditoria no Relatório do Auditor Independente; NBC TA 705 Modificações na Opinião do Auditor Independente; e NBC TA 706 - Parágrafos de Ênfase e Parágrafos de Outros Assuntos no Relatório do Auditor Independente.

ii Redação do parágrafo $3^{\circ}$, do artigo 21 da Resolução CMN n³.198, dada pela Resolução CMN n 4.720 .

iii $O$ teste de sinais empregado neste estudo, denominado como de Wilcoxon pelo software estatístico utilizado na análise (comando signtest no software Stata 14), não deve ser confundido com o teste de postos do mesmo autor (comando ranksum no software Stata 14).

iv Como a pandemia da Covid-19 alterou os prazos de publicação de demonstrações financeiras em diversos países, inclusive no Brasil, a verificação futura dos resultados efetivos da introdução da seção dos PAA em instituições financeiras, em 2020, ganhou novos desafios. Apesar de ser factível esperar dilatação nos audit delay em 2020, ficou mais difícil segregar os impactos decorrentes, exclusivamente, da exigência de publicação da nova seção.
} 